\title{
Kuru tarımdan Sulu Tarıma Dönüşümün Toprakta Çeyrek Asırlık Etkisinin Mikromorfolojik Ölçekte Tanımlanması
}

\author{
Ahmet Çelik ${ }^{*}$, Erhan Akça ${ }^{2}$

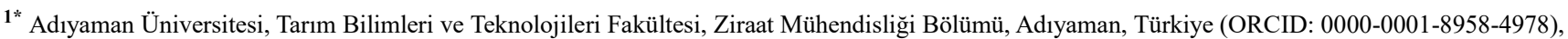 \\ ahmetcelik@adiyaman.edu.tr \\ ${ }^{2}$ Adıyaman Üniversitesi, Teknik Bilimler Meslek Yüksekokulu, Adıyaman, Türkiye (ORCID: 0000-0001-8988-4196), erakca@gmail.com
}

(İlk Geliş Tarihi 28 Ekim 2020 ve Kabul Tarihi 11 Ocak 2021)

(DOI: 10.31590/ejosat.816239)

ATIF/REFERENCE: Çelik, A. \& Akça, E. (2021). Kuru tarımdan Sulu Tarıma Dönüşümün Toprakta Çeyrek Asırlık Etkisinin Mikromorfolojik Ölçekte Tanımlanması. Avrupa Bilim ve Teknoloji Dergisi, (21), 207-215.

\begin{abstract}
$\ddot{O} \mathbf{z}$
Tarımsal üretimin üzerindeki baskılar gün geçtikçe artmaktadır. Tarım alanları sınıra dayanmış ve birim alandan daha çok üretim talep edilmektedir. Bunlara ek olarak iklim değişikliklerinin neden olduğu kurak dönem sayısındaki artış nedeniyle yarı kurak bölgelerde sulama ihtiyacını arttıracaktır. Ancak sulama kısa vadede üretimi arttırsa da uzun vadede başta tuzlanma olmak üzere toprak yapısını bozma, bitki besin elementlerinin yıkanmasının aralarında olduğu birçok olumsuz sonucu beraberinde getirmektedir. Toprakların sürdürülebilir kullanımı için uygulanan tarımsal yöntemlerin toprak kalitesini ne düzeyde etkilediği yapılacak detay çalışmalarla ortaya konulması toprak kalitesinin korunması hatta arttırılması için ön koşuldur. Adıyaman ilinin içinde yer aldığı Güneydoğu Anadolu Projesi kapsamında Atatürk Barajı göl havzasından yapılan sulama faaliyetleri 25 yıllık bir sürece dayanmaktadır. Sulu tarımın 25 yıllık süreçteki etkisi değerlendirmek için Adıyaman ili Kahta ilçesinin kuzeydoğusunda yer alan çalışma alanında 4 farklı noktadan 0-30 cm derinlikten toprak örnekleri alınmıştır. Örneklerde bazı fiziksel, kimyasal, mineralojik ve mikromorfolojik parametreleri araştırılmıştır. Çalışma alanındaki toprakların smektitin baskın kil minerali olduğu kil tekstürlü, kireçli, nötr ve hafif alkali pH'ya sahip oldukları belirlenmiştir. Mikroyapısal açıdan topraklarda sulama sonrası herhangi bir kireç birikimi veya yıkanma olgusu (kaplama/kütan) saptanmamıştır. Buna karşın kuru tarımdan sulu tarıma geçişle birlikte organik madde, organik karbon, azot ve $\mathrm{C} / \mathrm{N}$ düzeyleri azalma eğilimi gösterirken, elektriksel iletkenlik düzeyi kabul edilebilir sınırlar içinde olsa da artma eğilimi göstermiştir. Sonuç olarak, inceleme alanındaki elektriksel iletkenlik düzeyindeki artış eğilimi ve organik maddedeki azalma sulamanın tarımsal üretkenliği tehdit edebileceğini göstermektedir. Bunun önlenmesi için etkin sulama ve besleme programlarının saptanıp olası en hızlı süreçte hayata geçirilmesini gerektirmektedir.
\end{abstract}

Anahtar Kelimeler: Toprak Kalitesi, Mineraloji, Mikromorfoloji, Atatürk Barajı, Güneydoğu Anadolu Projesi

\section{Description of the Quarter-Century Effect of Conversion from Rainfed Farming to Irrigated Farming on a Micromorphological Scale}

\begin{abstract}
The pressures on agricultural production are increasing day by day. The agricultural lands have reached their limit and more production is demanded from per unit area. In addition to these, many studies have shown that the need for irrigation in semi-arid regions will increase due to the increase in the number of dry periods lead by climate change. However, although irrigation increases production in the short term, it brings many negative consequences, among which the destruction of soil structure, especially salinization, and leaching of plant nutrients in the long term. It is a prior condition to reveal the effect of agricultural management applied for the sustainable use of soils on soil quality through detailed studies to protect and even increase the soil quality. The irrigation activities carried out in the Atatürk Dam lake basin within the scope of the Southeastern Anatolia Project, which includes the province of Adiyaman, date back to 25 years. Soil samples were taken from 0-30 cm depth from 4 different points in the study area located in the northeast of Kahta district of Adiyaman province in order to evaluate the effect of irrigated agriculture in the 25 years. Some physical, chemical, mineralogical, and micromorphological parameters were determined in the samples. It has been determined that the soils in the study area have claytextured, calcareous, neutral and slightly alkaline $\mathrm{pH}$, where smectite is the dominant clay mineral. In terms of microstructure, no
\end{abstract}

\footnotetext{
** Sorumlu Yazar: Adıyaman Üniversitesi, Tarım Bilimleri ve Teknolojileri Fakültesi, Ziraat Mühendisliği Bölümü, Adıyaman, Türkiye, ORCID: 0000-0001-8958-4978, ahmetcelik@adiyaman.edu.tr
} 
carbonate accumulation or illuviation phenomenon (coating/cutans) was detected in the soil following irrigation. On the other hand, with the transition from rainfed farming to irrigated agriculture, organic matter, organic carbon, nitrogen and $\mathrm{C} / \mathrm{N}$ levels revealed a decrease, even though it was within acceptable limits, the electrical conductivity level tended to increase. As a result, the increasing trend in electrical conductivity in the study area and the decrease in organic matter indicate that irrigation can threaten agricultural productivity. To prevent this, effective irrigation and nutrition programs must be determined and implemented in the fastest possible time.

Keywords: Soil Quality, Mineralogy, Micromorphology, Atatürk Dam, Southeastern Anatolia Project

\section{Giriş}

Sürdürülebilir kalkınma için su ve toprak en kritik doğal varlık olarak kabul edilmektedir. Birleşmiş Milletlerin 2030 yılı için ortaya koyduğu 17 adet Sürdürülebilir Kalkınma Hedefinde su ve toprak hemen hemen hepsinde yer almaktadır. İklimsel değişikliğin arttığı ve gelecekteki kuraklık senaryoları üzerinde çalışıldığ 1 bir süreçte toprakların sürdürülebilir kullanımı için su kurak tarım alanları için bir önceliktir. Kuru tarım söz konusu olduğunda, toprağın kırılganlığı daha da önemli hale gelir, çünkü birçok tarım uygulaması toprağı yağış için hazırlama amacına sahiptir. Böylece mümkün olduğunca fazla su depolayabilir.

Dünya besin ihtiyacının yaklaşık \% 40'1, dünyada kullanılan tarımsal arazilerin yaklaşık \% 20'sinin sulanması sonucu elde edilmektedir. Sulama ile birlikte bitkisel üretim 1 ile 5 kat, yıllık gelir ise yaklaşık 6 kat kadar artabilmektedir (Powell ve ark., 1985; Bhattarai ve ark., 2002). Su ve tarım yönetimini mevcut imkanlarla potansiyele göre planlamak ülkenin gelecek yıllardaki gıda stratejisini de ortaya koyacaktır. Suyun etkin kullanımı sonucu ürünlerdeki verim artışının sağlanmasının yanısıra bölgenin sosyo-ekonomik gelişmişliğine katkı sağlaması için teknolojik sulama yatırımları ve sahada çiftçilere yönelik eğitim faaliyetleri özellikle Güneydoğu Anadolu Projesi gibi eğitim düzeyi ülke genelinden düşük olan bölgelerde oldukça önem taşımaktadır (Ünver, 1997; Altınbilek ve Tortajada, 2012).

Türkiye'de iklim koşulları, düzensiz yağış ve yüksek yaz sıcaklıkları ile özellikle Akdeniz ve Güneydoğu Anadolu bölgelerinde tarımsal üretimi etkileyen başlıca belirleyici faktörlerden biridir. Yarı kurak iklim şartlarına sahip alanlarda sulama imkânı yoksa, yetiştirilebilecek bitki türü sayısı önemli ölçüde azalmakta ve ekimler kışlık olarak yapılmaktadır (İnan, 2020). Bununla birlikte Türkiye'de kullanılabilir tarımsal alanların yaklaşık \% 85'lik bölümünde kuru şartlarda tarımsal üretim yöntemi ile yapılan uygulamalarda, birim alandan elde edilen ürün düzeyi düşüktür. Gelecekteki kuraklık senaryolarına göre bu verim ve ürün kayıpları daha da düşecek ve kriz boyutlarına ulaşabilecektir (Doran ve ark., 2009). Türkiye gıda güvenliğini güven altına almak için 8.5 milyon hektar sulu tarıma uygun arazilerinin 6.5 milyon hektarını sulamaya açmıştır (Aydın, 2019).

Adıyaman ve bölgesinde mülga KHGM (Köy Hizmetleri Genel Müdürlüğü) $(1990,1996,1997)$ tarafindan olası sulanacak alanlarla ilgili hazırlanan toprak etüt raporlarında üç bölgenin (Kahta Ovası, Çamgazi Ovası ve Besni-Keysun Ovası) fiziksel, kimyasal, biyolojik, mineralojik ve mikromorfolojik toprak özellikleri detaylı araştırmalarla belirlenmiştir. Ayrıca raporda arazi kullanım planlamalarına da yer verilmiştir. Yapılan etüt sonrası sulamaya açılan alanlarla ilgili çalışmalar oldukça sınırlıdır. Bölgede Çelik ve ark. (2017)' nın yapmış oldukları çalışmada, kuru tarımdan sulu tarıma dönüşümle organik madde, potasyum, çinko, bakır ve mangan düzeyleri azalma eğilimi gösterirken, elektriksel iletkenlik, hacim ağırlığı, azot, fosfor ve demir içeriklerinin artıı̆ı saptanmıştır. Dikkat çeken sonuçlardan biri de elektriksel iletkenlikteki artış ve organik maddede azalış her ne sebeple günümüz koşullarında verimi etkileme şansı olmasa da uzun vadeli tarımsal yönetim planlamalarında, Adıyaman'da sürdürülebilir tarım için bu olguların dikkate alınması gerekliliğini ortaya koymaktadır.

Adıyaman'da kuru tarımdan sulu tarıma dönüşümle birlikte sulanan tarımsal alanlarda son 20 yılda artış gözlemlenmiştir (Alan, 2019). Yapilan sulamayla beklenen birim alandan elde edilen verim düzeyi artmıştır. Yalnız toprak kalite düzeyindeki değişimlerle ilgili ihtiyaç duyulan araştırmaların yetersizliğinden dolayı sulamadan sonra tarımsal faaliyetlerin sürdürülebilirliği tartışma konusudur.

1991 yılında su tutulmaya başlayan Atatürk Barajı'ndan sonraki yıllarda kıyısı bulunan tarım alanlarına enerji kullanılarak su iletimi sağlanmıştır. Çalışma alanının bulunduğu bölgelerde yaklaşık 25 yılı aşkın bir zamandan günümüze kadar sulu tarım yapılmaktadır. Bu çalışmayla, yaklaşık 25 yıldan daha fazla bir süreçte sulu tarımla birlikte toprakların sahip olduğu davranışsal özelliklerin mikro yapısal açıdan değişimleri irdelenmiştir. Çalışma alanı Kahta Ovası'nın kuzeydoğusunda yer almakta olup, daha önce yapılan etüt alanı içinde olmadığından elde edilen sonuçların, sonraki araştırmacılar için altlık bilgi sağlayacağı düşünülmektedir.

\section{Materyal ve Metot}

\subsection{Materyal}

Çalışma alanı Adıyaman'ın Kahta ilçesine yaklaşık 55 km uzaklıkta, ilin kuzeydoğusunda yer almaktadır. $37^{\circ} 43^{\prime} 31.12^{\prime \prime}$ $37^{\circ} 42^{\prime} 45.20^{\prime \prime} \mathrm{N}$ enlemleri ile $38^{\circ} 48^{\prime} 30.89^{\prime \prime}-38^{\circ} 49^{\prime} 18.98^{\prime \prime}$ E boylamları arasında bulunmaktadır (Şekil 1). Çalıșma alanının denizden yüksekliği 590-616 m arasında değişmekte olup, 33 yıllık sıcaklık ve yağış ortalamas $17.5^{\circ} \mathrm{C}$ ve $670.5 \mathrm{~mm}$ 'dir (MGM, 2020). Köppen'in iklim sinıflandırılmasına göre Csa grubunda yer almaktadır. Adıyaman-Kahta genelinde toplam 569.541 dekarlık alanda tarım yapılmaktadır. Bu miktarın 88.000 dekarlık bölümünde sulu şartlarda tarla ve bahçe tarımı, 481.541 dekarlık alanda ise kuru koşullarda tarla ve bahçe tarımı yapılmaktadır (AİTOM, 2020). Araştırma alanında sulu koşullarda monokültür pamuk ve mısır tarımı yapılmakta olup, kuru koşullarda ise arpa, buğday, mercimek ve nohut tarımı yapılmaktadır. Çalışma alanı az taşı düzeyde, drenajı "orta drenaj" grubunda yer almaktadır. Eğim \% $0-2$ ve $\%$ 2-4 düzeyindedir. Toprak Taksonomisine göre (Soil Survey Staff, 2014), çalışma alanının toprak sıcaklık rejimi mesic, toprak nem rejimi xeric olarak sınıflandırılmıştır. Örnekleme alanında toprak sınıfı morfolojik yaklaşımla Toprak Taksonomisinde Vertic Haploxerept, IUSS Çalışma Grubu WRB (2015) sınıflamasında ise Vertic Cambisol (Fluvic) olarak sınıflandırılmıştır. Toprakların büyük bir bölümü işlenerek tarım yapılan Adıyaman-Kahta 
genelinde ki tarımsal uygulama yapılmayan arazilerde, erozyondan dolayı doğal toprak örtüsü bulunmayan veya çok sı $\breve{g}$ olan alanlar olup, büyük bir kısmı bozunmuş mera arazileridir
(Çelik ve Akça, 2017). Kil düzeyi yüksek topraklar büyük ölçüde karbonat içerikli kayaçların ayrışmasından oluşan kırmızı renkli smektit, illit ve düşük düzeyde kaolinit içeriklidir (KHGM, 1990).

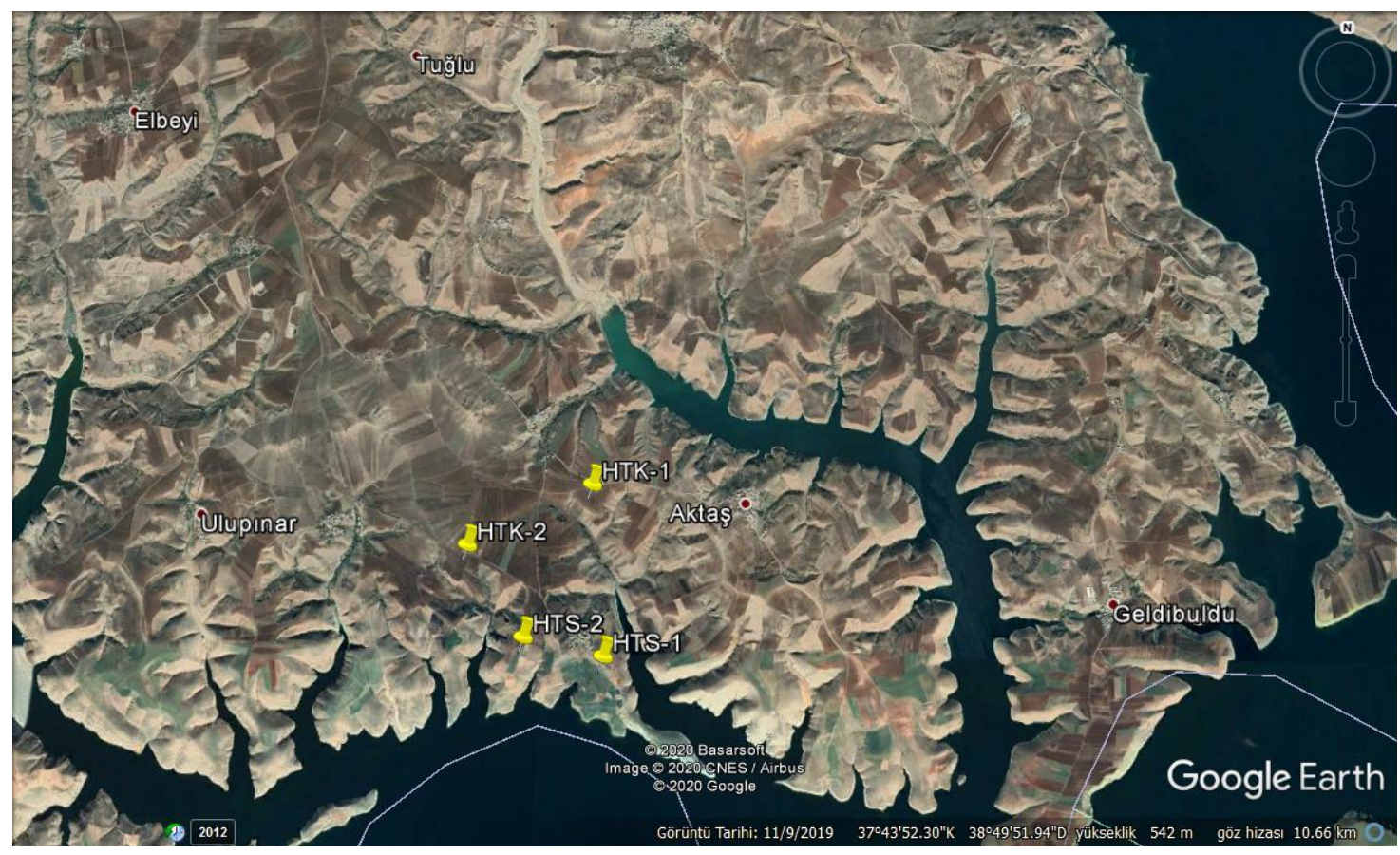

Şekil 1.Çalışma alanı ve örnek alım noktalarının konumu

\subsection{Metot}

Araştırma alanında sulama 1995 yılında başlamıştır. Toprak örnekleri 25 yıldan günümüze kadar sulu ve kuru koşullarda tarım yapılan arazilerden $0-30 \mathrm{~cm}$ derinlikten alınmıştır. Toprak analizleri ABD Tarım Bakanlığı Doğal Kaynakları Koruma Servisi Toprak Etüdü Laboratuvar (USDA-NRCS,1996) yöntemleriyle fiziksel (tekstür ve saturasyon) ve kimyasal $(\mathrm{pH}$,

\section{Araştırma Sonuçları ve Tartışma}

İnceleme alanında bulunan topraklar çamur akıntısı sonucu taşınmış bajadalar şeklinde, \% 0-2 ve \% 2-4 eğimli kısmen dalgalı yüzey topografyasına sahip orta düzey derinlikte topraklardır.

\section{1. Örneklerin Fiziksel ve Kimyasal Özellikleri}

Kuru ve sulu koşullarda tarım yapılan alanlardan alınan örneklerin bazı fiziksel ve kimyasal özellikleri Tablo 1'de verilmiştir. Kuru ve sulu tarım yapılan alanlardaki topraklar killi bünyeye sahiptir. Toprak reaksiyonu $(\mathrm{pH})$ değerleri kuru tarımda ortalama 7.39, sulu tarımda 7.65 olup, Ülgen ve Yurtsever (1995) tarafindan kuru koşullarda "nötr", sulu koșullarda "hafif alkali" olarak değerlendirilmiştir. Daha önce Kahta bölgesinde KHGM (1997), Çelik ve Akça (2017) tarafından yapılan çalışmada pH değerleri benzer şekilde elde edilmiştir. Kuru tarım yapılan toprakların ortalama EC değerleri $0.86 \mathrm{dS} \mathrm{m}^{-1}$ iken, sulu tarım yapılan toprakların ise $1.03 \mathrm{dS} \mathrm{m}^{-1}$ saptanmıştır (Tablo 1). Tuzluluk düzeyinde aradaki farkın sulamada kullanılan suyun kalitesi, bilinçsiz ve aşırı sulama, ihtiyaçtan fazla kullanılan gübrelerin neden olabileceği düşünülmektedir. Bununla birlikte organik madde, organik karbon, kireç, EC, azot) analizleri yapılmıştır. Alınan örneklerin mineralojik analizleri Maden Tetkik Arama Laboratuvarlarında X-1şını kırınım aygıtıyla 3-70 aralığında toz örneklerde yapılmıştır (Jackson, 1979). Adıyaman Üniversitesi Merkezi Araştırmalar laboratuvarında örnekler polarize mikroskopta ve tarama elektron mikroskobunda (SEM) incelenmiş ve örneklerin mikro-yapısal gelişimi ve gözenek boyut ve dağılım özellikleri FitzPatrick (1993) tarafindan verilen terminolojiye uygun olarak yapılmıştır.

çalışma alanı toprakları "tuzsuz" olarak sınıflandırılmıştır (Richards, 1954). Çelik ve ark. (2017) Besni Keysun-Yoldüzü Ovası'nda yaptıkları araştırmada sulu tarıma geçişten sonra pamuk ve misırda monokültür uygulamaları sonucu tuzluluk düzeyinin yaklaşık 3 kat arttığını belirlemişlerdir. Cox ve ark. (2018)'nın ABD'de kurak tarım alanlarının sulanması sonrasında toprak kalite düzeylerinde meydana gelen değişimlerle ilgili çalışma yapmışlardır. Bu araştırmada, özellikle killi topraklarda yüksek buharlaşma-terleme hızları, yüksek tuzluluk oranına sahip su ile yoğun sulama ve sinırlı infiltrasyon bitkinin büyümesi, toprak gözenekliliği ve geçirgenliğinin azalması, zayıf havalandırmaya yol açmış ve bir geri dönüşüm mekanizması ile tuz oluşumunu hızlandırdığ 1 saptanmıştır. $\mathrm{Bu}$ nedenle tarımın sürdürülebilirliği uygun su, toprak ve ürün yönetimi uygulamalarına bağlıdır. Araştırma alanındaki kuru tarım topraklarının ortalama kireç içerikleri \% 1.37 olup, sulu tarım topraklarının ise \% 1.56 olarak saptanmıştır. Ortalama kireç düzeyleri Ülgen ve Yurtsever (1995) tarafindan "kireçli" olarak değerlendirilmiştir (Tablo 1). Elde edilen sonuçlar KHGM (1997), Tazebay ve Saltalı (2011) ve Çelik ve Baran (2018)' in çalışmalarıyla uyum göstermiştir. 
Tablo 1. Örneklerin Fiziksel ve Kimyasal Özellikleri

\begin{tabular}{|c|c|c|c|c|c|c|c|c|c|c|c|c|c|}
\hline $\begin{array}{c}\text { Örnek } \\
\text { No }\end{array}$ & $\begin{array}{c}\text { Derinlik } \\
\text { (cm) }\end{array}$ & $\begin{array}{c}\text { Saturasy } \\
\text { on }\end{array}$ & $\begin{array}{c}\text { Tekstür } \\
\text { Sınıfı }\end{array}$ & $\begin{array}{c}\% \\
\text { Kum }\end{array}$ & $\begin{array}{c}\% \\
\text { Silt }\end{array}$ & $\begin{array}{c}\% \\
\text { Kil }\end{array}$ & $\begin{array}{c}\mathrm{pH} \\
(1: 2.5)\end{array}$ & 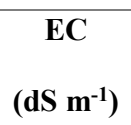 & $\begin{array}{l}\mathrm{CaC} \\
\mathrm{O}_{3} \%\end{array}$ & $\begin{array}{c}\text { OM } \\
\%\end{array}$ & $\begin{array}{c}\text { OC } \\
\%\end{array}$ & $\begin{array}{l}\mathbf{N} \\
\%\end{array}$ & $\mathrm{C} / \mathrm{N}$ \\
\hline $\begin{array}{l}\text { HTK } 1 \\
\text { (Kuru) }\end{array}$ & $0-30$ & 50 & $\mathrm{C}$ & 46 & 7 & 47 & 7.27 & 0.94 & 1.18 & 1.59 & 0.92 & 0,09 & 10.22 \\
\hline $\begin{array}{l}\text { HTK } 2 \\
\text { (Kuru) }\end{array}$ & $0-30$ & 60 & $\mathrm{C}$ & 11 & 21 & 68 & 7.51 & 0.78 & 1.57 & 1.40 & 0.81 & 0,07 & 11.60 \\
\hline $\begin{array}{l}\text { HTS } 1 \\
\text { (Sulu) }\end{array}$ & $0-30$ & 58 & $\mathrm{C}$ & 26 & 10 & 64 & 7.51 & 1.08 & 1.57 & 1.19 & 0.69 & 0,06 & 11.5 \\
\hline $\begin{array}{l}\text { HTS } 2 \\
\text { (Sulu) }\end{array}$ & $0-30$ & 64.5 & $\mathrm{C}$ & 12 & 14 & 74 & 7.78 & 0.97 & 1.55 & 1.02 & 0.59 & 0,06 & 9.83 \\
\hline
\end{tabular}

Çalışma alanındaki toprakların organik madde düzeyleri kuru tarım uygulamalarında ortalama $\% \quad 1.5$, sulu tarım uygulamalarında ise \% 1.11 olarak elde edilmiştir (Tablo 1). Sánchez-González ve ark. (2017) özellikle monokültür olarak çalıştıkları mısır denemelerinde organik maddenin miktarını ve kalitesini değiştirdiğini saptamışlardır. Benzer sonuçlar Çelik ve ark. (2017)'nın yaptıkları çalışmada saptanmış ve bu azalmanın büyük olasılıkla inceleme alanında yoğun sulu tarıma dönüşüm sonrası arazi kullanım düzeyinin artması, iklim ile ilgili gelişen sürece bağlı olarak ayrışma düzeyinin artması, anızın yakılması veya topraktan uzaklaştırılması nedeniyle organik madde miktarının azalma gösterdiğine dikkat çekmişlerdir. Organik madde düzeyinin Avrupa Toprak Bürosu'nun belirlediği değerlerin altında saptanması organik karbon yönetiminin gerekliliğini ortaya koymaktadır. Araştırma alanındaki toprakların organik karbon içerikleri incelendiğinde, kuru tarım uygulamalarında ortalama \% 0.87 , sulu tarım koşullarında ise \% 0.64 olarak belirlenmiştir. Sulu tarım uygulamalarında toprak organik karbon içeriği kaybı, toprağın sürdürülebilir bitki üretimi için besin sağlama yeteneğini sınırlayabilir. Devamında daha düşük verim ve gıda güvenliğini etkileyebilir. Daha az organik karbon aynı zamanda toprakta bulunan canlı organizmalar için daha az gıda anlamına gelir, böylece toprak biyoçeşitliliğini azaltır (European Communities, 2009). Kuru ve sulu koşullardaki toprakların N düzeyleri sırasıyla ortalama \% 0.08 ve $\% 0.06$ olarak saptanmıştır. Belirlenen \% N değerleri FAO (1990)'nun yeterlilik gruplandırmasına göre "az" düzeyde değerlendirilmiştir (Tablo 1). Sulu tarım uygulamalarında azot düzeyinin düşük düzeyde saptanmasının nedeni aşırı kültivasyon koşulları, monokültür ekim programı ve iklimsel faktörlerden kaynaklı olduğu düşünülmektedir. Pan ve ark. (2013), Çelik ve Akça (2017) yaptıkları çalışmalarda benzer sonuçlar elde etmişlerdir. Örnekleme alanındaki toprakların $\mathrm{C}: \mathrm{N}$ oranları irdelendiğinde, kuru ve sulu tarım uygulamalarında sırasıyla ortalama 10.91 ve 10.67 olarak belirlenmiştir. Kuru tarım uygulamalarında sık toprak işleme faaliyetlerinin olmayışı ile ayrışma ve parçalanmanın sulu tarım koşullarına göre oldukça yavaş olması ve bu nedenle topraktaki biyokütlenin artmasına neden olduğu düşünülmektedir. Yarı kurak iklim özelliği gösteren bölgede aralıksız yapılan sulu tarım uygulamaları (bilinçsiz arazi işleme vb.) ve yüksek oksidasyonla topraklar $\mathrm{C}$ ve $\mathrm{N}$ kaybetmektedirler (Sakin ve ark., 2011). Azalan C ve N düzeylerini uygun değerlere çıkarmak için toprağa organik gübre programlarının uygulanması gerektiği düşünülmektedir.

\section{2. Örneklerin Mineralojik ve Mikromorfolojik Özellikleri}

\subsubsection{Mineralojik Özellikler}

Adıyaman ve yöresi genel olarak Marn-Marnokalkerli yüksek araziler, Fırat ve yan kollarının konglomeratik terasları, çamur akıntısı-bajadalar, alüviyal yelpaze, genç alüviyal çökeller üzerinde oluşmuştur (KHGM,1996 ve 1997). Bölgede daha önce yapılan çalışmalarda, toprakların kil içeriklerinin yüksek olduğu saptanmıştır. Kil düzeyleri ve çeşitleri, toprağı oluşturan ana materyal ve fizyoğrafik birimlere bağlı olarak değişmektedir. Kil minerali saptamasına yönelik yapılan çalışmalarda bölge topraklarında dört tip kil minerali; smektit, illit, kaolinit ve paligorskit belirlenmiştir (KHGM, 1997; Çelik, 2012; Çelik ve ark., 2015). Bu çalışmada alınan toprak/kil örneklerinin mineralojik analiz sonuçları dikkate alındığında değişen cins ve miktarlarda HTK-2 ve HTS-2 örneklerinde baskın birincil mineral kuvars ve kalsit olarak saptanmıştır (Şekil 3,5). HTK-1 ve HTS-1 örneklerinde ise, baskın birincil mineral sadece kuvars olarak belirlenmiştir (Şekil 2,4). Tüm örneklerde başat kil minerali smektittir. Bunu illit, kaolinit ve düşük düzeyde paligorskit izlemektedir. Kurak ve yarı kurak bölge topraklarda ayrışma düzeyinin yüksek miktarda gerçekleşmesiyle elde edilen bulguların doğruluğunu daha önce yapılan çalışmaların sonuçları kanitlamaktadir.

İnfiltrasyondaki hızlı azalma, hızlı agrega tahribatı ve temel toprak parçacıklarının yoğun olarak toplanmasından dolayı kaynaklanabilir. İnfiltrasyondaki azalma topraklardaki smektit tipi kil minerallerinin varlığına dayanabilir. Smektit içeriği yüksek topraklarda daha fazla erozyon oluşacağı düşünülmektedir (Mermut ve ark., 1995). 


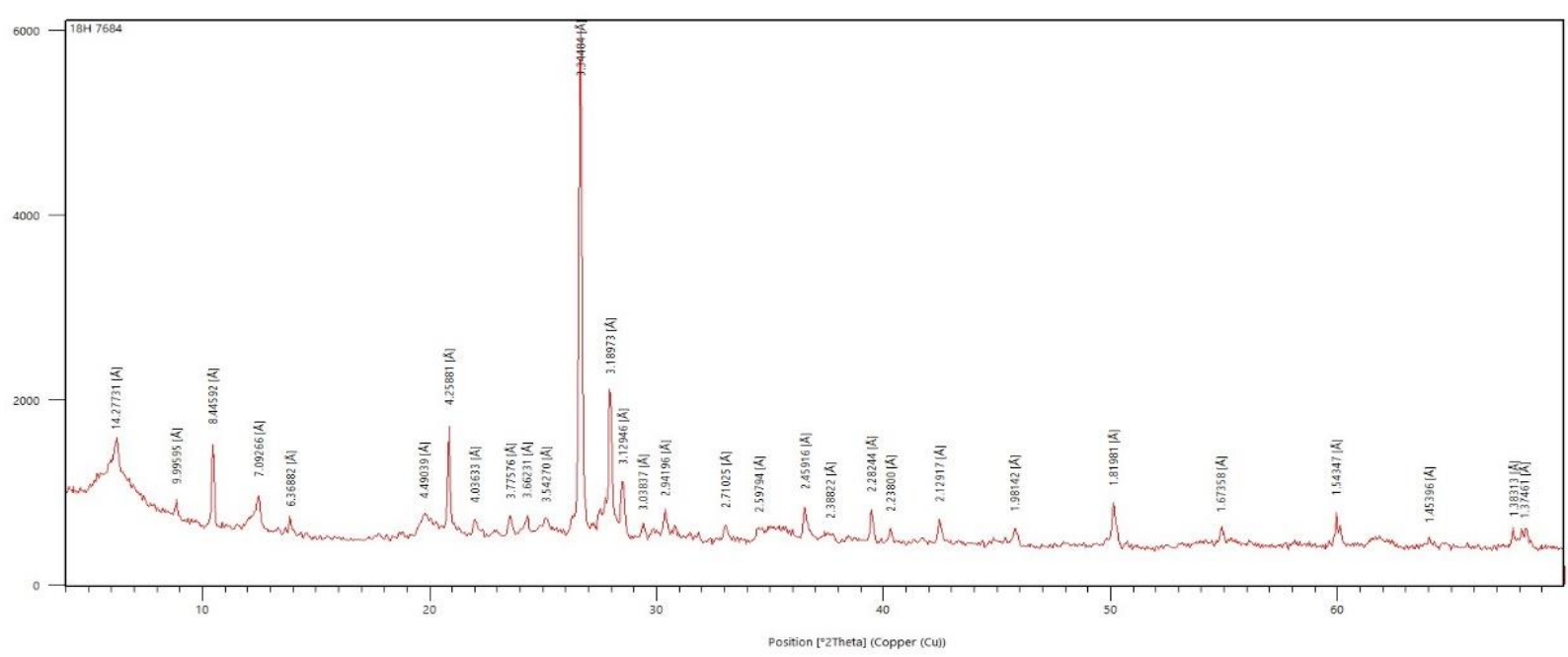

Şekil 2. HTK 1 Örneğinin Toz (öğütülmüş) XRD Grafiği

Counts

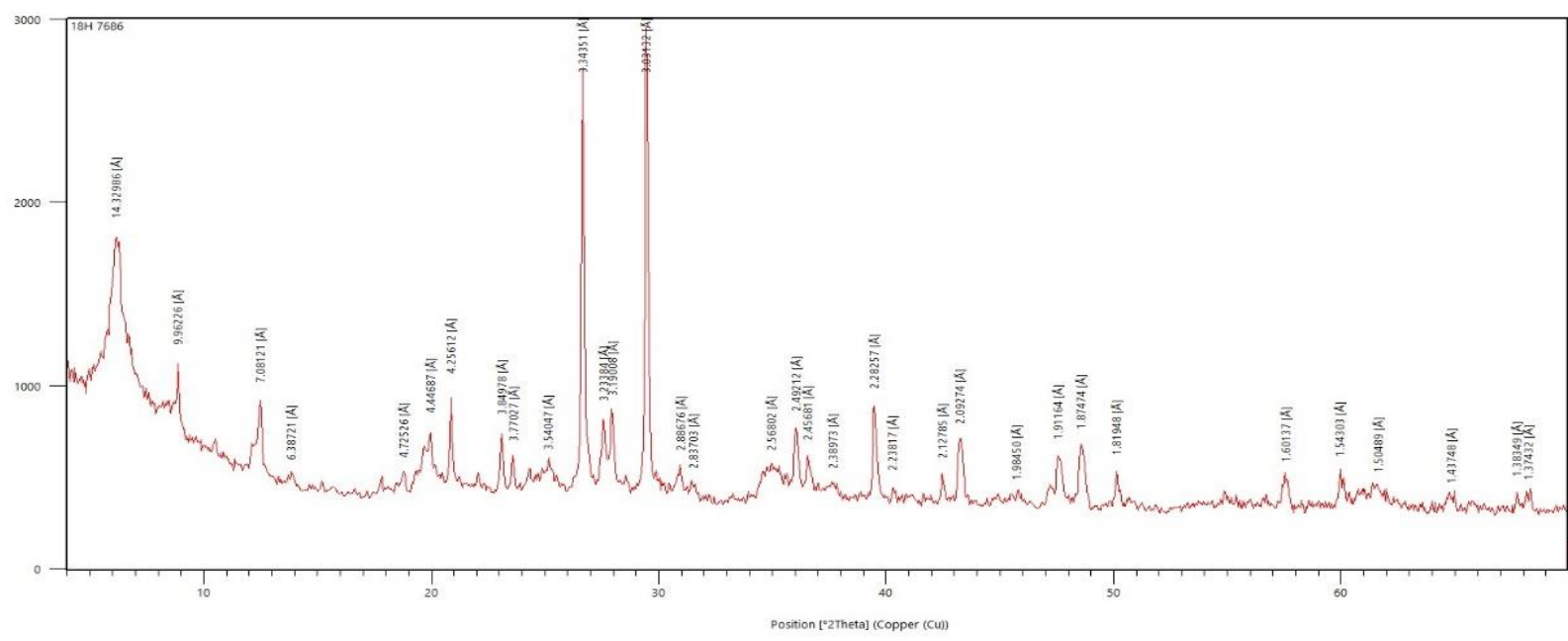

Şekil 3. HTK 2 Örneğinin Toz (öğütülmüş) XRD Grafiği

counts

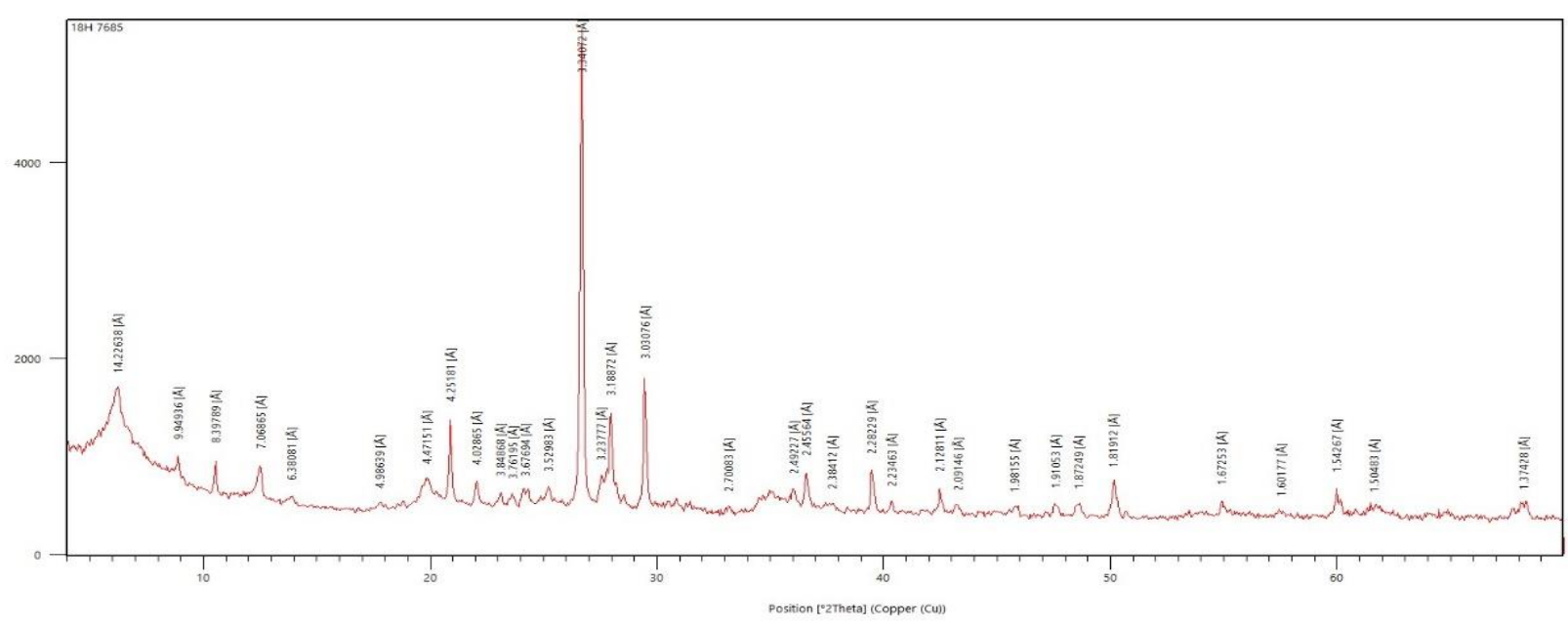

Şekil 4. HTS 1 Örneğinin Toz (öğütülmüş) XRD Grafiği 


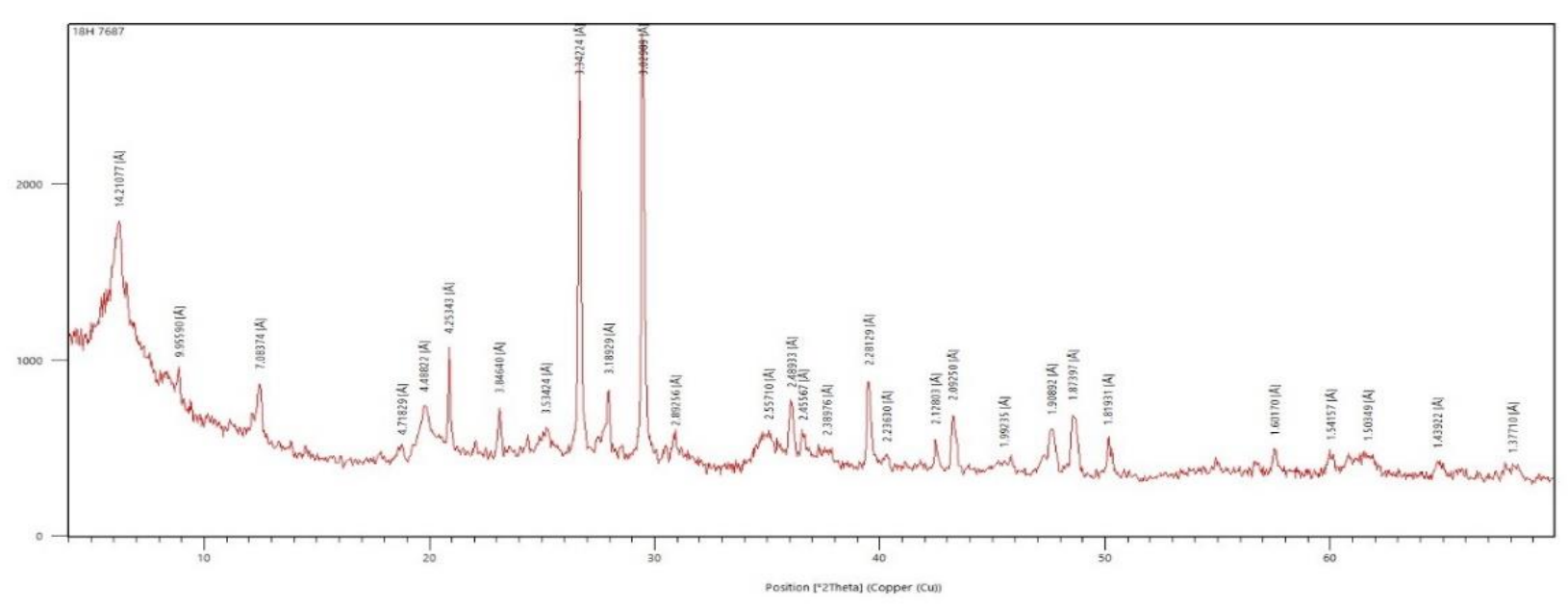

Şekil 5. HTS 2 Örneğinin Toz (öğütülmüss) XRD Grafiği

\subsection{2. Örneklerin Bazı Mikromorfolojik Özellikleri}

Araştırma alanından alınan örneklerin mikromorfolojik analizleri Scanning Electron Microscopy (SEM)'de incelenmiş olup, toprakların mikro-yapısal gelişim düzeyleri ve gözenek boyut ve dağılım özellikleri incelenmiştir (FitzPatrick, 1993) (Şekil 6, 7, 8, 9).

İnceleme alanındaki toprakların Vertisol ordosunun özelliklerine sahip, baskın kil tipinin smektit içermesi ve yüksek düzeyde plastiklik özelliği göstermesi agregatlaşma düzeyini artırma eğilimindedir. Yapılan önceki çalışmalarda, birbirini izleyen kuru ve sslak döngüler sırasında, bir Vertisol yüzeyinin yapısının yavaş yavaş masiften karmaşık kırıntıya, bloklu ve yassı yapıya değiştiğini ve pedlerin boyutunun giderek azaldığını göstermiştir (Hussein ve Adey, 1998). Araştırma alanında en yoğun agregatlaşma kuru koşullarda tarım yapılan HTK-1 ve HTK-2 örneklerinde saptanmıştır (Şekil 6,7). Yüksek smektitli kilin varlığının, makro-agregatlar içinde mineralize edilebilir toprak organik maddesinin ve buna bağlı olarak toprak organik karbon düzeyinin korunmasını arttırdığı bildirilmiştir (Chevallier ve ark., 2004). Çalışma alanında kuru koşullardaki (HTK-1 ve HTK-2) organik madde ve organik karbon düzeyleri bunun kanıtıdır (Tablo 1). HTK-2 örneğinde mikroagregat sayısı diğer örneklere göre daha yüksek düzeyde belirlenmiştir (Şekil 7). Çalışmada dikkat çeken diğer bir ayrıntı kuru koşullardaki örneklerde agregat yapısının bloklu yapıya doğru eğilimidir. $\mathrm{Bu}$ değişikliğin temelinde yapının dayanım açısından korunduğunun göstergesi olduğu düşünülmektedir. Örneklerin SEM görüntülerinde organik yapılar tam olarak belirlenememesine karşın HTS-1 ve HTS-2 örneklerinde düşük düzeyde organik yapılar saptanmıştır (Şekil 8,9). Bu durum büyük olasılıkla iklimsel faktörlere bağlı olarak organik maddenin hızla ayrışarak humin formlarına dönüşememesi olarak açıklanabilir. Kuru tarım yapılan HTK-1 ve HTK-2 örneklerinde agregatlaşma düzeyinin sulu tarım yapılan HTS-1 ve HTS-2 örneklerine göre daha yaygın olmasının diğer bir nedeni daha az yoğunlukta toprak işleme faaliyetleridir. Oluşum ve yapısal yönden mikroyapıda herhangi bir kireç birikimi veya yıkanma olgusu (kaplama/kütan) saptanmamıştır. Özetle, araştırma alanı topraklarında agregat oluşumu açısından kil ve organik madde düzeyi ve aynı zamanda arazi işleme yoğunluğunun etkili olduğu görülmektedir. 


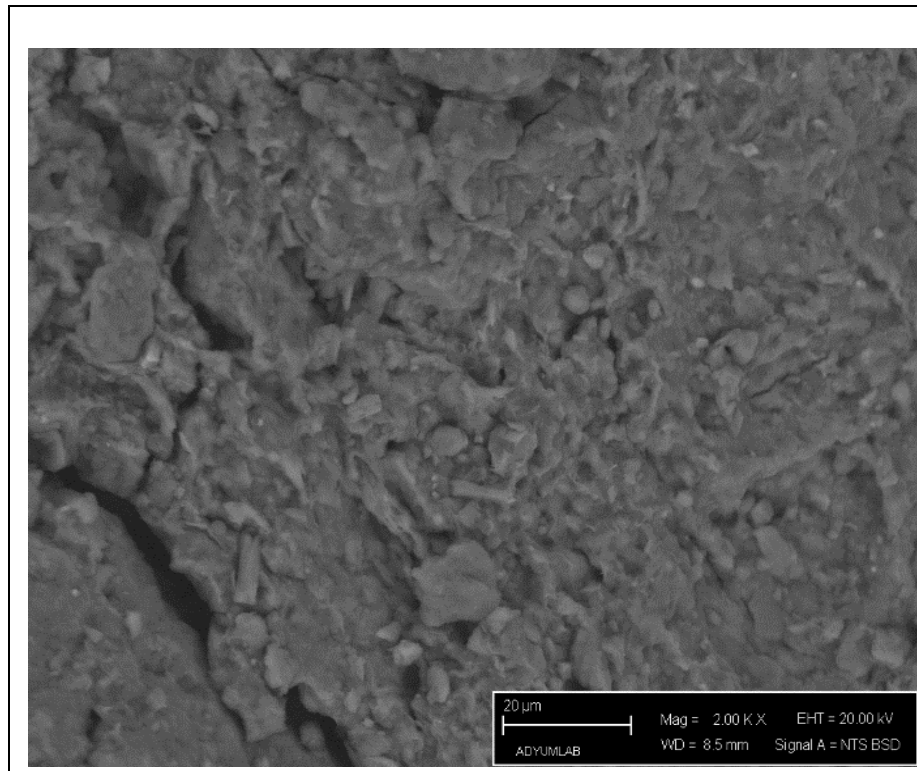

Şekil 6. HTK-1 Kuru koşullarda tarım yapılan toprakların SEM görüntüsü

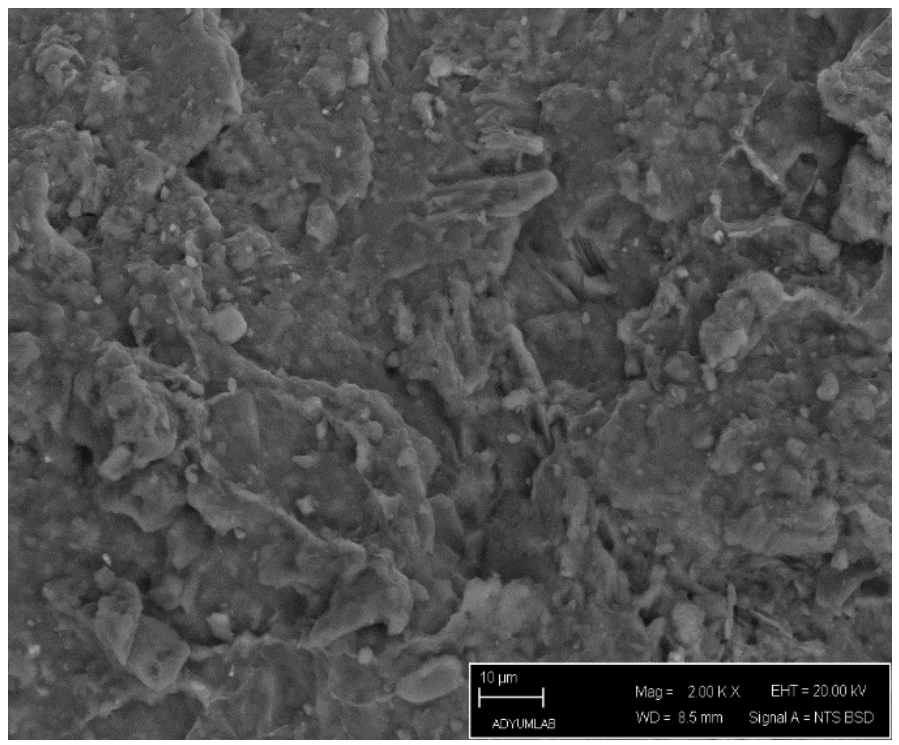

Şekil 8. HTS-1 Sulu koşullarda tarım yapılan toprakların SEM görüntüsü

\section{Sonuç}

Tarıma dayalı ekonomiye sahip ülkelerde sulu tarım toplumun refah düzeyinin artmasında lokomotif etki göstermektedir. Kurak ve yarı-kurak bölgelerdeki ülkeler ki Türkiye bu ülkeler arasındadır sulu tarım konusunda yüksek düzeyde yatırım yapmaktadırlar. Su ve tarım yönetimini mevcut imkanlarla potansiyele göre planlamak ülkenin gelecek yıllardaki tarımsal üretim stratejisini de ortaya koymaktadır. Tarımsal faaliyetlerde ürün-fayda ilişkisi birim alandan elde edilen ürün düzeyine ve verimliliğe göre değişkenlik gösterir. Sürdürülebilir toprak kalitesinin korunması, arazi kullanımındaki iyileştirmeler ve elde edilecek verimle sektörde faaliyet gösteren insanların sosyoekonomik yaşam düzeyleri ve milli gelire sağlayacakları katkı düzeyinin artmasını sağlayacaktır. Bununla birlikte sulama dikkatli ve bilimsel ölçütlerde yapılmadığında tarihte Sümer

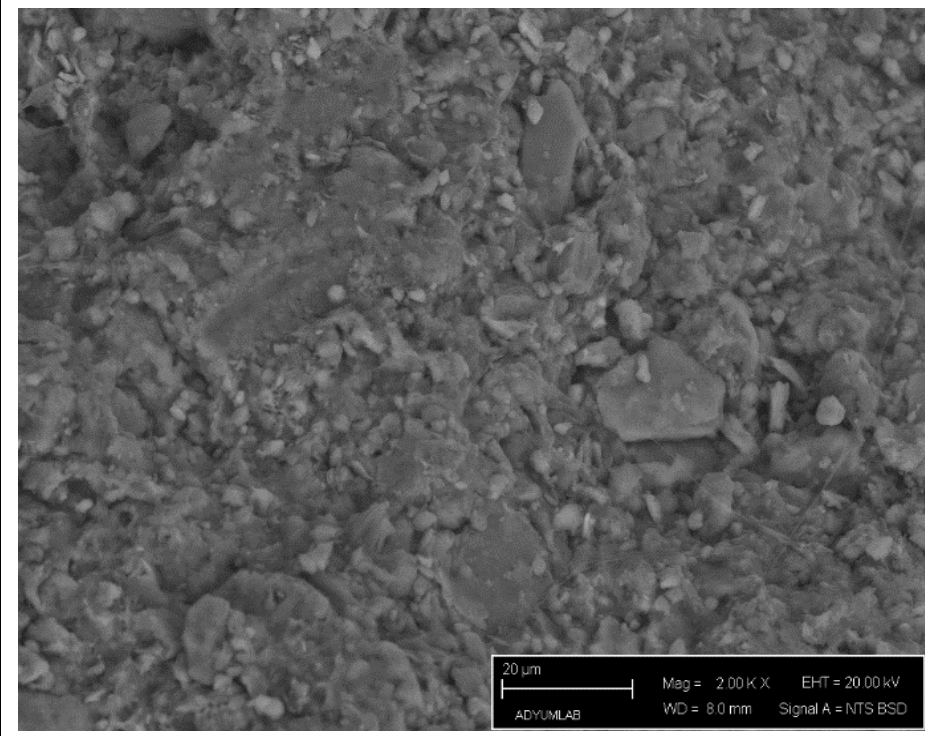

Şekil 7. HTK-2 Kuru koşullarda tarım yapılan toprakların SEM görüntüsü

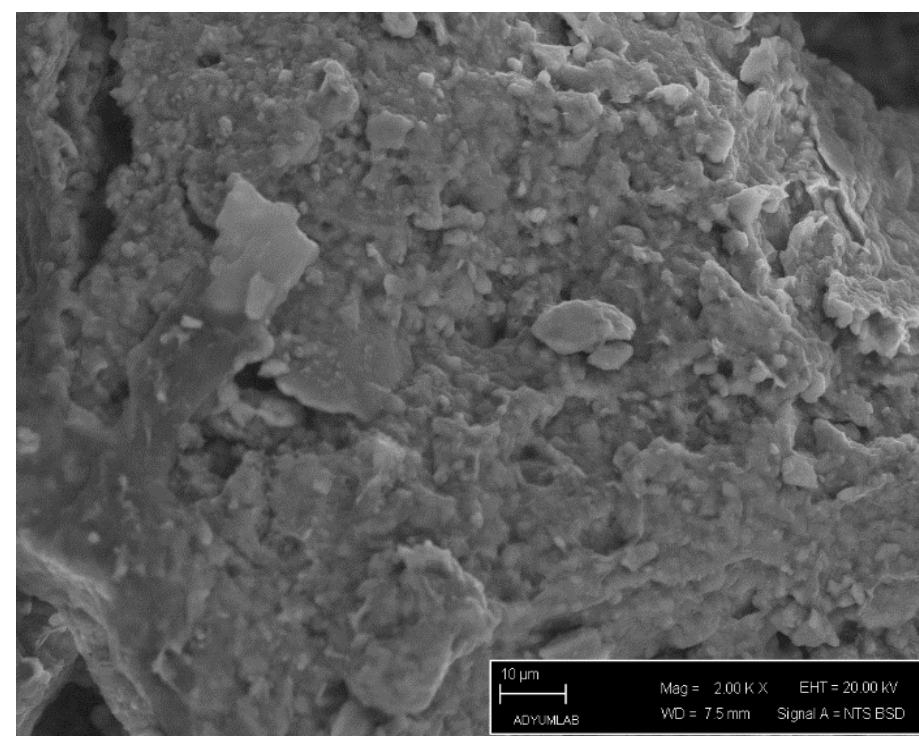

Şekil 9. HTS-2 Sulu koşullarda tarım yapılan toprakların SEM görüntüsü
Uygarlığında da görüleceği üzere topraklarda tuzlanma, yapı bozulmasına, kirlenmeye ve sonuçta çölleşmeye giden süreci tetiklemektedir. Çalışma sonrasında hâlihazırda sulanan topraklarda belirgin bir kalite bozulması olmamasına karşın eğilimin tuzluluğun artması, organik maddenin azalması ve mikroyapının geçirimsiz tabaka oluşturmaya başladığı saptanmış ve görülmüştür. Bu sorunların geriye döndürülmesi için özellikle monokültür pamuk tarımının yapıldığı alanlarda su istemeyen bitkilerin kullanıldığ vadede toprakların bozunumunu ve tuzluluk seviyesinin artmasını önleyecektir. Yörede bilinçsiz ve aşırı yapılan gübreleme ile belki üretimin ilk dönemlerinde iyi verim elde edilmesi mümkün, ancak uzun süreçte toprağın fiziksel, kimyasal ve biyolojik özellikleri üzerine ne tür bir etki edeceği önceden bilinmemektedir. Yalnız bu olumsuzluklar ortaya çıktığında ise problemlerin kısa süreçte çözümü mümkün olmadığı gibi toprakların geri kazanımı için 
yapılan/yapılacak çalışmalar uzun bir zamana yayılacaktır. Bölgede korumalı tarım uygulamalarının gelişimi ve ivme kazanması ve aynı zamanda toprak verimliliği ve organik madd $\epsilon$ yönetimi, toprakların sürdürülebilirliği ve su yönetimi açısından fayda sağlayacaktır.

\section{Teşekkür}

Araştırma alanında örnekleme sırasında katkılarından dolayı Halil Tanyıldız ve Miraç Kılıç’a teşekkür ederiz.

\section{Kaynakça}

AİTOM (2020). Adıyaman İl Tarım ve Orman Müdürlüğü bilgi kitabi.

Alan, A. (2019). Adıyaman tarımının genel görünümü sorunlar ve öncelikler. Adıyaman'ın geleceğinde tarım ve gida paneli bildiri kitabi. 30 Kasım 2019, 25-28.

Altinbilek, D., Tortajada, C. (2012). The Atatürk Dam in the context of the Southeastern Anatolia (GAP) project. In Impacts of large dams: A global assessment (pp. 171199). Springer, Berlin, Heidelberg.

Aydın, M. (2019). Tarımsal Sulama. Türk Tarım Orman Dergisi. Mayıs-Haziran 12019: 10-26.

Bhattarai, M., Sakthivadivel, R., Hussain., I. (2002). Irrigation impacts on income inequality and poverty alleviation: Policy issues and options for improved management of irrigation systems. Working Paper 39. Colombo, Sri Lanka: International Water Management Institute.

Chevallier, T., Blanchart, E., Albrecht, A., Feller, C. (2004). The physical protection of soil organic carbon in aggregates: a mechanism of carbon storage in a Vertisol under pasture and market gardening (Martinique, West Indies). Agriculture, Ecosystems \& Environment, 103(2), 375-387.

Cox, C., Jin, L., Ganjegunte, G., Borrok, D., Lougheed, V., Ma, L. (2018). Soil quality changes due to flood irrigation in agricultural fields along the Rio Grande in western Texas. Applied Geochemistry, 90, 87-100.

Çelik, A. (2012). Adıyaman ilinin tarım dışı alanlarındaki tuğlaseramik hammadde kaynaklarının kullanım potansiyellerinin belirlenmesi, Çukurova Üniversitesi Fen Bilimleri Enstitüsü, Toprak Bilimi ve Bitki Besleme Ana Bilim Dalı (Doktora Tezi), Adana.

Çelik, A., Akça, E., Yıldırım, Y., Büyük, G., Kapur, S. (2015). Adıyaman Bölgesi'nde Tarım Dışı Alanlardaki Kil Yataklarının Kil Mineralojisi: Tuğla-Seramik Hammaddesi Olarak Değerlendirileme Potansiyelleri, 16. Ulusal Kil Sempozyumu, Çanakkale Onsekiz Mart Üniv. Yayınları: 127 Sempozyum Kitabı, 128-138s, Çanakkale.

Çelik, A., İnan, M., Sakin, E., Büyük, G., Kırpık, M., Akça, E. (2017). Kuru tarımdan sulu tarıma geçiş sonrası toprak özelliklerindeki değişimler: Adıyaman örneği. Toprak Bilimi ve Bitki Besleme Dergisi, 5(2), 80-86.

Çelik, A., Akça, E. (2017). Adıyaman'da eğimli akarsu seki topraklarının sürdürülebilir kullanımı için öneriler. Yüzüncü Yll Üniversitesi Tarım Bilimleri Dergisi, 27(1), 130-141.

Çelik, A., Baran, M.F. (2018). Adıyaman İli Toprak Yapısı ve Tarımsal Mekanizasyon Durumu. Ziraat, Orman ve Su Ürünlerı Alanında Akademık Çalışmalar. Gece Kitaplığı, Ankara, s.61-74.

Doran, İ., Koca, Y. K., Kılıç, T. (2009). Olası İklim Değişiminin Diyarbakır Tarımına Etkileri. V. Ulusal Coğrafya Sempozyumu, 16-17 Ekim 2008, 369-377, Ankara.
European Communities (2009). Reproduction is authorised provided the source is acknowledged.

s://esdac.jrc.ec.europa.eu/projects/SOCO/FactSheets/ENFactShe et-03.pdf

FAO (1990). Micronutrient, assessment at the country level, an intemational study. FAO Soils Bulletin, 63. Rome.

FitzPatrick, E. A. (1993). Soil Microscopy and Micromorphology. Chichester No. 631.43 F5. John Wiley \& Sons. 433P.

Hussein, J., Adey, M.A. (1998). Changes in microstructure, voids and b-fabric of surface samples of a Vertisol caused by wet/dry cycles. Geoderma, 85(1), 63-82.

İnan, M. (2020). Yarı Kurak Koşullarda Ekim Zamanlarının Çörekotu (Nigella sativa L.) Verim ve Verim Özelliklerine Etkisi. Türk Tarım ve Doğa Bilimleri Dergisi, 7(1), 32-37.

Jackson, M.L. (1979). Soil Chemical Analysis. Adv. Course. Dept.of Soil Sci.Mad., Wisconsin, 247p.

KHGM (1990). Adıyaman Çamgazi Ovası Sulama Projesi Sahası Detaylı Temel Toprak Etütleri. Köy Hizmetleri Genel Müdürlüğü Toprak Etüd Şubesi Ankara, s. 212.

KHGM (1996). Adıyaman-Besni, Keysun ve Kızılin Ovası Sulama Proje Sahası Detaylı Toprak Etütleri, Köy Hizmetleri Genel Müdürlüğü Etüd ve Proje Dairesi Başkanlığı, Ankara, s. 168.

KHGM (1997). Adıyaman Kâhta Ovası Sulama Proje Sahası Detaylı Toprak Etütleri, Köy Hizmetleri Genel Müdürlüğü Etüd ve Proje Dairesi Başkanlığı, Ankara, s. 250.

Mermut, A. R., Luk, S. H., Römkens, M. J. M., \& Poesen, J. W. A. (1995). Micromorphological and mineralogical components of surface sealing in loess soils from different geographic regions. Geoderma, 66(1-2), 71-84.

MGM (2020). Meteoroloji Genel Müdürlüğü Kayıtları. Ankara.

Pan, J.L., Dai, W.A., Shang, Z.H., Guo, R.Y. (2013). Review of research progress on the influence and mechanism of field straw residue incorporation on soil organic matter and nitrogen availability. Chinese Journal of Eco-Agriculture, 21(5), 526-535.

Powell, R.A., Jenson, R.C., Gibson, A.L. (1985). The economic impact of irrigated agriculture in NSW. Australia: New South Wales Irrigators' Council Limited.

Richards, L.A. (1954). Diagnosis and improvements saline and alkali soils. U.S. Dept. Agr. Handbook, 60.

Sakin, E., Deliboran, A., Sakin, E.D., Aslan, H. (2011). Carbon and nitrogen stocks and $\mathrm{C}: \mathrm{N}$ ratios of Harran plain soils. Romanian Agricultural Research, 28:171-180.

Sánchez-González, A., Chapela-Lara, M., Germán-Venegas, E., Fuentes-García, R., del Río-Portilla, F., Siebe, C. (2017). Changes in quality and quantity of soil organic matter stocks resulting from wastewater irrigation in formerly forested land. Geoderma, 306, 99-107.

Soil Survey Staff (2014). Keys to Soil Taxonomy, 12th ed. USDA-Natural Resources Conservation Service, Washington, DC.

Tazebay, N., Saltalı, K. (2011). Adıyaman-Besni ilçesi kuru ve sulu tarım alanı topraklarının verimlilik açısından değerlendirilmesi. Ulusal Toprak ve Su Sempozyumu, 25-27 Mayıs, Ankara.

Unver, I.O. (1997). Southeastern Anatolia Project (GAP). International Journal of Water Resources Development, 13(4), 453-484.

USDA-NRCS (1996). Soil Survey Laboratory Manual. Soil Survey Investigation Report No. 42. Version 3.0. 693 P. Washington. 
Ülgen, N., Yurtsever, N. (1995). Türkiye Gübre ve Gübreleme Rehberi (4. Baskı), T.C. Başbakanlık Köy Hizmetleri Genel Müdürlüğü Toprak ve Gübre Araştırma Enstitüsü Müdürlüğü Yayınları, Genel Yayın No: 209, Teknik Yayınlar No: T.66, Ankara, s. 230.
WRB (2015). World Reference Base For Soil Resources. International Soil Classification System For Naming Soils And Creating Legends For Soil Maps. Food and Agriculture Organization of the United Nations. Rome, Italy. 